\title{
On the morphology of the juvenile stages of Ampulex compressa (Fabricius 1781) (Hymenoptera, Ampulicidae)
}

\author{
EDUARDO GONÇALVES PATERSON FOX ${ }^{1}$, SANDOR CRISTIANO BUYS ${ }^{2}$, JACE- \\ NIR REIS DOS SANTOS MALLET ${ }^{3} \&$ SUZETE BRESSAN-NASCIMENTO ${ }^{4}$ \\ ${ }^{\prime}$ Departamento de Biologia / UNESP. Address: 24A Avenue 1515 - Bela Vista 13506-900 - Rio Claro, SP - Bra- \\ zil. \\ ${ }^{2}$ Departamento de Entomologia / UFRJ. Address: Caixa-Postal: 68044 São Cristóvão 21944-970 - Rio de Ja- \\ neiro, RJ - Brazil \\ ${ }^{3}$ Departamento de Entomologia / Fundação Oswaldo Cruz. Address: Caixa-Postal: 926 Manguinhos 21045- \\ 900 - Rio de Janeiro, RJ - Brazil. \\ ${ }^{4}$ Instituto de Biofísica Carlos Chagas Filho / UFRJ. Address: Cidade Universitária - CCS Ilha do Fundão \\ 21949-900 - Rio de Janeiro, RJ - Brazil.
}

\begin{abstract}
Ampulex compressa is a cockroach-hunting ampulicid wasp. In this survey we describe its egg, mature larva, along with the $1^{\text {st }}$ and $2^{\text {nd }}$ larval instars and cocoon, with emphasis on the characters considered important to the phylogeny of apoid wasps. It shares the following traits with the Sphecidae: reduced head setae, absence of antennal papilla, three antennal sensilla on antennal orbit, broad and strongly emarginate labrum, and spinneret with prominent raised lips. In common with other Ampulicidae, it has integument of the body granulose and without setae, mandibles with four or five teeth and lacking basal setae, maxillary palp larger than galea and discrete parietal bands. Distinct from the other Ampulicidae, it has a deep median longitudinal groove in the area above the salivary lips, a distinct group of five sensilla on the subgenal area, and lacks spines on the spiracular peritreme.
\end{abstract}

Key words: Hymenoptera; Sphecidae; Ampulicidae; larval description; phylogeny

\section{Introduction}

The Ampulicidae is a mainly tropical family of solitary cockroach-hunting wasps with six recognised genera and nearly 200 species (Gayubo et al. 1998; Ohl 2002). They are believed to have a comparatively basal position within the Apoidea although their exact parentage is still unclear (Ohl and Bleidorn, 2006; Alexander 1992; Melo 1999). 